addition to written reports is required to gain a comprehensive view of performance. In the United States this type of monitoring by a physician is recommended for all cases of cardiac arrest treated by emergency medical technicians using advanced skills. No such recommendations exist in the United Kingdom. Monitoring of electrocardiograms and cassette tapes is time consuming and requires additional equipment. ${ }^{3}$ Lack of resources or medical support, in addition to the lack of official directives, may result in ambulance services failing to monitor standards, and the full potential of advanced trained ambulance staff will not be achieved.
We thank Marks and Spencer for funding this research, Miss S Smith for preparing the manuscript, and Dr D D'Auria, Mr K G Smith, and the staff of the London Ambulance Service for allowing access to records and equipment.

Ambulance Staff Training Committee. Extended training in ambulance aid. Bristol: NHS Training Authority, 1987

2 Cummins RO. EMT defibrillation: national guide-lines for implementation. Am 7 Emerg Med 1987:5:254-7.

3 Cummins RO, Austin D, Graves JR, et al. An innovative approach to medical control: semi-automatic defibrillators with solid-state memory modules for recording cardiac arrest events. Ann Emerg Med 1988;17:818-24.

Accepted 23 December 1988)

\section{Screening for colonic cancer in patients with Barrett's oesophagus}

\section{A F Robertson, R C S Ayres, C L Smith}

Department of Medicine II, Southampton General Hospital, Southampton SO9 4XY

D A F Robertson, MD, lecturer in medicine R C S Ayres, MRCP, medical registrar C L Smith, MD, senior lecturer in medicine

Correspondence to: $\mathrm{Dr}$ Robertson.

BrMed f 1989;298:650
In 1985 Sontag et al reported an association between Barrett's oesophagus and colonic neoplasia, but their study did not include a control population. 'In another uncontrolled series no colorectal cancers were seen in 36 patients with Barrett's oesophagus, although $33 \%$ of these patients had colorectal adenomas. ${ }^{2}$ We performed colonoscopy prospectively in our patients with Barrett's oesophagus, none of whom had symptoms of colonic neoplasia, and compared the results with those obtained in a control group of patients thought to have the irritable bowel syndrome.

\section{Subjects, methods, and results}

Barrett's oesophagus was defined as columnar epithelium occurring in a tubular oesophagus at least $3 \mathrm{~cm}$ above the manometrically defined lower oesophageal sphincter. ${ }^{+}$We studied 32 patients $(21$ men and 11 women), whose mean age was 61 (range 29-81). None had a history of colorectal neoplasia. Two control patients thought on clinical grounds to have the irritable bowel syndrome, and matched for age and sex, were chosen for each patient with Barrett's oesophagus; their mean age was 55 (range 28-81). No additional screening tests, such as testing for faecal occult blood, were done to exclude colonic neoplasia.

Eight patients with Barrett's oesophagus (25\%) had 12 colorectal tumours, three of which were malignant and nine benign (table). All were successfully treated, two by local resection, one by subtotal colectomy, and

Clinical details of patients and controls with colorectal tumours

\begin{tabular}{|c|c|c|c|c|}
\hline Case No & $\begin{array}{l}\text { Age (years) } \\
\text { and sex }\end{array}$ & Site & Histological findings & Treatment \\
\hline \multicolumn{5}{|c|}{ Patients } \\
\hline 1 & $79 \mathrm{M}$ & Sigmoid colon & Tubulovillous adenoma with severe & Endoscopic polypectomy \\
\hline 2 & & (Descending colon & dysplasia at both sites & \\
\hline 2 & $66 \mathrm{M}$ & Descending colon & $\begin{array}{l}\text { Tubulovillous adenoma with severe } \\
\text { dysplasia }\end{array}$ & Endoscopic polypectomy \\
\hline 3 & $53 \mathrm{M}$ & Sigmoid colon & $\begin{array}{l}\text { Tubular adenoma and mild } \\
\text { dysplasia at two sites }\end{array}$ & Endoscopic polypectomy \\
\hline 4 & $72 \mathrm{~F}$ & Hepatic flexure & Adenomatous polyp & Endoscopic polypectomy \\
\hline 5 & $74 M$ & Sigmoid colon & Adenomatous polyp & Endoscopic polypectomy \\
\hline \multirow{3}{*}{6} & \multirow{3}{*}{$52 M$} & Transverse colon & Tubular adenoma with mild & Right hemicolectomy \\
\hline & & & dysplasia & \\
\hline & & Hepatic flexure & Dukes's A carcinoma & \\
\hline 7 & $44 M$ & $\left\{\begin{array}{l}\text { Splenic flexure } \\
\text { Sigmoid }\end{array}\right.$ & Dukes's B carcinoma & Subtotal colectomy \\
\hline \multirow[t]{2}{*}{8} & $71 M$ & Sigmoid colon & Dukes's A carcinoma & Sigmoid colectomy \\
\hline & & & Controls & \\
\hline 9 & $52 M$ & Sigmoid colon & Adenomatous polyp & Endoscopic polypectomy \\
\hline 10 & $64 \mathrm{~F}$ & Descending colon & Adenomatous polyp & Endoscopic polypectomy \\
\hline 11 & $66 \mathrm{M}$ & Rectum & Adenomatous polyp & Endoscopic polypectomy \\
\hline
\end{tabular}

five by endoscopic polypectomy. Three of the 64 controls $(5 \%)$ had single adenomatous polyps, which were removed endoscopically. The relative risk of colonic tumour was 5.3 in the patients with Barrett's oesophagus ( $95 \%$ confidence interval 1.94 to $8 \cdot 69$ ).

\section{Comment}

We found a high prevalence of colorectal tumours in our patients with Barrett's oesophagus, in keeping with the findings of Sontag et al. ${ }^{1}$ Our study was entirely prospective, and the association between colonic neoplasia and Barrett's oesophagus seemed to be genuine and not due to some hidden bias; this may not have been the case in the uncontrolled study by Sontag et $a l$, in which seven of 10 carcinomas were identified retrospectively.

Selecting an appropriate control group was difficult, and we considered that colonoscopic examination of asymptomatic people was unjustified because of the risks and discomfort entailed. We thus selected patients who had been referred for investigation and in whom the irritable bowel syndrome had been diagnosed on clinical grounds. The controls were on average six years younger than the study group, and this could have affected the prevalence of colonic tumours: the prevalence of colonic neoplasia related to age in asymptomatic subjects is unknown. The difference in age between the two groups, however, is unlikely to have accounted for all of the observed differences in prevalence.

The aetiology of both Barrett's oesophagus and carcinoma of the colon remains unknown. The symptoms of dyspepsia or chest pain are unlikely to have been caused by the colonic carcinoma or adenoma, and in each case the finding of a colonic lesion was incidental. An inherited or acquired common aetiological agent, such as a dietary factor or a tendency to neoplastic or metaplastic change throughout the gastrointestinal tract, may have been the cause. There was no evidence of dysplasia in biopsy specimens or resected colonic epithelium not affected by adenomatous or carcinomatous change.

It has been recommended that frequent oesophagoscopy should be undertaken in patients with Barrett's oesophagus to detect early oesophageal carcinoma or dysplasia. None of our patients had high grade dysplasia or oesophageal carcinoma but eight had colonic neoplasia. Colonoscopy may therefore be a more worthwhile screening procedure for cancer than oesophagoscopy in Barrett's oesophagus.

1 Sontag SJ, Schnell TG, Chesec G, et al. Barrett's (esophagus and colonic tumours. Lancet 1985; ; $946-9$.

2 Tripp MR, Sampliner RE, Kogan FJ, Morgan TR. Colorectal neoplasia and Barreti's Ses

Barrett's oesophagus. Am f Gastroenterol 1986;81:1063-4. Towards positive
Manning AP, Thompson WG, Heaton KW, Morris AF. Towat Manning AP, Thompson WG, Heaton KW, Morris AF.

diagnosis of the irritable bowel. Br.Med f 1978;ii:653-4.
Spechler SJ, Goval RK. Barrett's oesophagus. N Engl f Med 1986;315:362-71.

Accepted 23 December 1988 